\title{
Detection of RNA species unique to a behavioral task ${ }^{1}$
}

BARRY MACHLUS AND JOHN GAITO

YORK UNIVERSITY

A DNA-RNA successive competition experiment in which $D N A$ is hybridized first with RNA from nonbehaving rats and then with RNA from shock avoidance trained rats suggests that unique RNA species are synthesized during this task.

A number of individuals have suggested that RNA plays a unique role in learning phenomena (e.g., Hyden \& Egyhazi, 1962; Landauer, 1964; numerous others). In spite of many research efforts, however, there is still no conclusive evidence to implicate RNA in learning (Dingman \& Sporn, 1964; Gaito, 1966). Unfortunately, it is difficult to evaluate the role of RNA in learning because of the many contradictory experimental results.

One means of attempting to determine the role of RNA in learning events is by DNA-RNA hybridization procedures (Gillespie \& Spiegelman, 1964; Bonner, 1966; Gaito, 1966). If one heats a solution of rat brain DNA at $95^{\circ} \mathrm{C}$ for $5 \mathrm{~min}$, the double stranded DNA will split into single strands. If this DNA is then poured onto nitrocellulose membranes, these membranes will "trap" single strands but will allow any double strands to pass through. If a membrane with attached DNA is placed in a solution of RNA, those RNA molecules which are complementary in base sequence to DNA sites will become firmly attached and be resistant to ribonuclease (RNase) treatment. If this DNA-RNA hybrid is put in another solution of the same RNA, no further hybridization will occur because all DNA sites complementary to the RNA will be occupied. On the other hand, if this hybrid is added to a different solution of RNA which is complementary to other DNA sites, further hybridization will occur.

Putting this procedure within a behavioral framework, the rationale is the following. If there exist unique species of brain RNA which are involved during learning, and RNA from the brain of a nonlearning animal is hybridized with single strand DNA, then when RNA from the brain of a learning animal is added to this hybrid, the unique RNA species should adhere to the DNA. An important aspect of this successive competition hybridization procedure is that only the RNA from learning animals is labeled. Thus the presence of label in the twice hybridized DNA would suggest that RNA species not present in the brain of nonlearning animals has been synthesized in learning animals during the task.

In this study a learning task was chosen which included components that would maximize sensory stimulation (shock avoidance) and involve some motor activity as well so as to maximize the behavioral differences between learning and nonlearning animals. Thus, although the basic question "Are there unique RNA species for learning?" was of interest, this study was attempting to answer first a more gross question "Are there unique RNA species produced during a gross behavioral event?"

Method

In these experiments DNA was extracted from brain tissue using four cold phenol steps, the last one preceded by RNase treatment. RNA was obtained by repeated phenol treatments, one of which was at $60^{\circ} \mathrm{C}$ so as to separate rapidly labeled messenger RNA. The hybridization procedure was that of Gillespie \& Speigelman (1964).

In a preliminary experiment with rat gastrointestinal DNA labeled with thymidine $-\mathrm{H}^{3}$, it was determined that all, or almost all, of the labeled DNA adhered to nitrocellulose membranes (Schleicher \& Schuell, B-6, $25 \mathrm{~mm}$ ) following the pouring of heat denatured DNA on these membranes. A second preliminary experiment found that when $50 \mu \mathrm{g}$ of DNA was hybridized separately with $0,10,25,50$, and $75 \mu \mathrm{g}$ of RNA, the $\mu \mathrm{g}$ of RNA hybridized appeared to reach a plateau at $50 \mu \mathrm{g}$ of RNA. At this point and at $75 \mu \mathrm{g}$, approximately $1.10 \mu \mathrm{g}$ of RNase resistant RNA was hybridized with the $50 \mu \mathrm{g}$ of DNA.

In Experiment 1, eight pairs of littermate rats (Wistar strain; age, 100 days; weight, about $290 \mathrm{~g}$ ) were used. All experimental rats were injected intracranially with $200 \mu \mathrm{c}$ of orotic acid $5-\mathrm{H}^{3}$ (specific activity, $13.8 \mathrm{c} / \mathrm{mM}$ ) in physiological saline. Orotic acid is a precursor of uridylic acid for RNA. Control animals were injected with unlabeled orotic acid. Sixty minutes later each animal was placed in a one-way active shock avoidance apparatus. After 15 min of adaptation in the shock chamber of the apparatus, the experimental animal (learning-L) was given 15 trials in $15 \mathrm{~min}$ and sacrificed by immersion in liquid nitrogen for $10 \mathrm{sec}$. The control rat (nonlearning-NL) did not receive this training and was sacrificed at the end of $30 \mathrm{~min}$ in the shock chamber. All eight learning animals showed eight or more avoidance responses in the 15 trials (mean, 10.1; SD, 1.2).

The brain of each rat was divided into two approximately equal halves by a vertical cut. Each portion consisted of a cerebral hemisphere and one half of the cerebellum and brain stem. DNA was extracted from one portion and RNA from the other. 
Table 1. Hybridization Procedures and Mean Micrograms of RNA Hybridized +

\begin{tabular}{|c|c|c|c|}
\hline Hybrid & Mean & SD & Expected Mean \\
\hline \multicolumn{4}{|l|}{ (a) Experiment 1} \\
\hline 1. DNA $A_{L}-\mathrm{RNA}_{\mathrm{L}}^{*}$ & 1.55 & 0.12 & 1.10 \\
\hline 2. $\mathrm{DNA}_{\mathrm{NL}}-\mathrm{RNA} \mathrm{NL}$ & 0.99 & 0.08 & 1.10 \\
\hline 3. $\mathrm{DNA}_{\mathrm{L}}-\mathrm{RNA}_{\mathrm{NL}}-\mathrm{RNA}_{\mathrm{L}}{ }_{\mathrm{L}}$ & 0.70 & 0.11 & 0.00 \\
\hline 4. $\mathrm{DNA}_{\mathrm{NL}}-\mathrm{RNA}_{\mathrm{L}}{ }^{*}-\mathrm{RNA}_{\mathrm{NL}}$ & 1.45 & 0.13 & 1.10 \\
\hline \multicolumn{4}{|l|}{ (b) Experiment 2} \\
\hline 1. $\mathrm{DNA}_{\mathrm{NL}}-\mathrm{RNA}_{\mathrm{NL}}^{*}$ & 1.25 & 0.04 & 1.10 \\
\hline 2. $\mathrm{DNA}_{N L}-\mathrm{RNA}_{\mathrm{L}}-\mathrm{RNA}_{\mathrm{NL}}$ & 0.00 & 0.00 & 0.00 \\
\hline 3. $\mathrm{DNA}_{L}-\mathrm{RNA}_{\mathrm{L}}-\mathrm{RNA}_{\mathrm{NL}}{ }^{*}$ & 0.00 & 0.00 & 0.00 \\
\hline 4. $\mathrm{DNA}_{\mathrm{L}}-\mathrm{RNA}^{*} \mathrm{NL}^{-\mathrm{RNA}_{\mathrm{L}}}$ & 1.12 & 0.02 & 1.10 \\
\hline 5. $\mathrm{DNA}_{\mathrm{NL}}-\mathrm{RNA}_{\mathrm{NL}}{ }^{-\mathrm{RNA}^{*}} \mathrm{NL}$ & 0.93 & 0.07 & 1.10 \\
\hline
\end{tabular}

+ Asterisk indicates the presence of labelled precursor in RNA; SD is standard deviation.

With the two rats in each of the eight pairs, four hybrids were obtained as shown in Table 1a. Hybrid 3 was the crucial one. The dpm (above background) of the membranes of Hybrids 1, 3, and 4 were determined in a liquid scintillation spectrometer. The RNA in Hybrid 2 was eluted with $0.01 \mathrm{M}$ Tris buffer ( $\mathrm{pH}$ 7.3) and determined by absorbance readings in a spectrometer. In each hybrid $50 \mu \mathrm{g}$ of RNA was hybridized with $50 \mu \mathrm{g}$ of DNA; the dpm in $50 \mu \mathrm{g}$ of RNA was used to determine the $\mu \mathrm{g}$ of RNA complexed with the $50 \mu \mathrm{g}$ of DNA.

\section{Results and Discussion}

Table 1a indicates for each hybrid condition the mean $\mu \mathrm{g}$ RNA hybridized and the expected mean $\mu \mathrm{g}$ RNA hybridized. This latter value (1.10) was obtained in the second preliminary study. In each of the eight pairs, the $\mu \mathrm{g}$ RNA hybridized in the crucial double hybridized DNA (Hybrid 3) was greater than zero. Such results are significant at $\mathrm{p}<.01$ with a binomial test. Likewise in each pair, the values in Hybrids 1 and 4 were approximately the same, and both values were greater than that for the nonbehaving rats (Hybrid 2). Hybrids 1 and 2 and 2 and 4 were different $(p<.01)$; Hybrids 1 and 4 were not significantly different.

These results suggest that during the last $15 . \mathrm{min}$ of the $90 \mathrm{~min}$ period for incorporation of the labeled precursor, additional species of RNA appeared in the brain of the learning animals (Hybrid 3). This conclusion is corroborated by the differences between Hybrids 1 and 2 and Hybrids 2 and 4. The difference between the two in each case is approximately as great as the $\mu \mathrm{g}$ RNA hybridized in (3). Hybrids 1 and
4 showed approximately the same hybridization, suggesting that intra- and interanimal hybridization (within littermates) give similar results.

To check on possible artifacts, Experiment 2 was performed with two pairs of littermate rats. This check consisted of reversing the entire procedure by injecting the nonlearning animal with the labeled precursor and the learning animal with the nonlabeled material. Two crucial hybrids were 2 and 3 (Table $1 \mathrm{~b}$ ). If the results of Hybrid 3 in the previous experiment were an artifact, one would expect that label would be detected in both hybrids. The dpm in each case was not above background. Three other hybrids checked on the hybridization of RNA from nonlearning rats. The values obtained were relatively close to 1.10 in all cases.

The results of Experiments 1 and 2 suggested that during the behavioral task in this study, RNA species were produced which were different from those present in the brains of nonlearning rats. During the first $75 \mathrm{~min}$ of the incorporation period the two groups of animals were treated the same. Thus the differences probably reflect the synthesis of RNA during the last $15 \mathrm{~min}$ during which learning was occurring. Presumably the labeled RNA during this period is of the messenger type, although different species of ribosomal and transfer RNAs cannot be excluded because the extraction procedures did not differentiate these three types.

One cannot maintain that these results indicate that the RNA species detected are unique to learning processes because sensory stimulation (via shock) and motor activity were confounded in the learning task. Further successive competition experiments are required to control for the sensory-motor aspects in this task.

\section{References}

BONNER, J. Molecular biological approaches to the study of memory. In J. Gaito (Ed.), Macromolecules and behavior. New York: AppletonCentury-Crofts, 1966.

DINGMAN, W., \& SPORN, M. B. Molecular theories of memory. Science, 1964, 144, 26-29.

GAITO, J. Molecular psychobiology. Springfield, Ill.: C. C. Thomas, 1966.

GILLESPIE, D., \& SPIEGELMAN, S. A quantitative assay for DNA-RNA hybrids with DNA immobilized on a membrane. J. Mol. Biol., 1965, $12,829-842$.

HYDEN, H., \& EGYHAZI, E. Nuclear RNA changes of nerve cells during a learning experiment in rats. Proc. Nat. Acad. Sci., 1962, 48, 1366-1373.

LANDAUER, T. K. Two hypotheses concerning the biochemical basis of memory. Psychol. Rev., 1964, 71, 167-179.

Note

1. This research was supported by Office of Naval Research Contract Nonr 4935 (00) and Grant No. APB-122 from the National Research Council of Canada. 